Article

\title{
Phase Inversion-Induced Porous Polybenzimidazole Fuel Cell Membranes: An Efficient Architecture for High-Temperature Water-Free Proton Transport
}

\author{
Sangrae Lee ${ }^{\dagger}$, Ki-Ho Nam ${ }^{\dagger}$, Kwangwon Seo, Gunhwi Kim and Haksoo Han * \\ Department of Chemical and Biomolecular Engineering, Yonsei University, 50 Yonsei-ro, Seodaemun-gu, \\ Seoul 120-749, Korea; daniel2000alpha@gmail.com (S.L.); nam023497@gmail.com (K.-H.N.); \\ kwseo@yonsei.ac.kr (K.S.); rlarjszzz@nate.com (G.K.) \\ * Correspondence: hshanpublication@gmail.com; Tel.: +82-2-312-1417 \\ t These authors contributed equally to this work.
}

Received: 30 June 2020; Accepted: 17 July 2020; Published: 19 July 2020

\begin{abstract}
To cope with the demand for cleaner alternative energy, polymer electrolyte membrane fuel cells (PEMFCs) have received significant research attention owing to their high-power density, high fuel efficiency, and low polluting by-product. However, the water requirement of these cells has necessitated research on systems that do not require water and/or use other mediums with higher boiling points. In this work, a highly porous meta-polybenzimidazole ( $m$-PBI) membrane was fabricated through the non-solvent induced phase inversion technique and thermal cross-linking for high-temperature PEMFC (HT-PEMFC) applications. Standard non-thermally treated porous membranes are susceptible to phosphoric acid (PA) even at low concentrations and are unsuitable as polymer electrolyte membranes (PEMs). With the porous structure of $m$-PBI membranes, higher PA uptake and minimal swelling, which is controlled via cross-linking, was achieved. In addition, the membranes exhibited partial asymmetrical morphology and are directly applicable to fuel cell systems without any further modifications. Membranes with insufficient cross-linking resulted in an unstable performance in HT-PEMFC environments. By optimizing thermal treatment, a high-performance membrane with limited swelling and improved proton conductivity was achieved. Finally, the $m$-PBI membrane exhibited enhanced acid retention, proton conductivity, and fuel cell performance.
\end{abstract}

Keywords: polybenzimidazole; porous membrane; thermal cross-linking; phosphoric acid; proton transport; high-temperature polymer electrolyte membrane fuel cells

\section{Introduction}

As the demand for cleaner alternative energy sources increases, multiple fields of research have focused on potential renewable energy sources for the new generation. For applications that require instant power conversion from fuel, fuel cells are considered as a perfect candidate. Among the different types of fuel cells that have been developed, polymer electrolyte membrane fuel cells (PEMFCs) have captured the interest of several researchers due to their high-power density, high fuel efficiency, and low polluting by-product, compared to other fuel cells. Perfluorosulfonic acid polymer membranes, such as Nafion ${ }^{\circledR}$, are widely used in PEMFCs as the polymer electrolyte membrane (PEM) for various applications owing to their favorable properties. However, such fuel cells are still associated with several problems that need to be resolved, such as low carbon monoxide tolerance, requirement of humidification equipment, expensive fluorinated polymers, and limited operating temperatures (below $100{ }^{\circ} \mathrm{C}$ ), which leads to limited activity of expensive catalysts [1-5]. Particularly, the fundamental 
limiting aspect of perfluorosulfonic acid polymer is its requirement for water as the medium for proton transportation. Thus, systems which do not require water and/or use other mediums with higher boiling points are being researched.

High-temperature PEMFCs (HT-PEMFCs) can operate above $100^{\circ} \mathrm{C}$ without humidification using acids such as phosphoric acid (PA) or ionic liquids as the medium. In comparison to conventional PEMFCs, they offer several advantages, including faster electrode kinetics, higher impurity tolerance, and a simplified systematic design [6-10]. Therefore, researchers have focused on developing PEMs with favorable characteristics for these HT-PEMFCs [11], such as polybenzimidazole (PBI). PBI possesses the necessary properties for HT-PEMFC application, such as high thermal and mechanical stabilities, low fuel cross-over, and resistance to chemical degradation $[12,13]$. However, it suffers from limitations such as lower proton conductivity than commercially available Nafion ${ }^{\circledR}$. Thus, substantial efforts have been devoted toward improving the performance of PBI. Methods such as incorporating additives such as metal organic framework [14], graphene oxide [15,16], and other inorganic variants [17,18] have led to vast improvements in performance compared to base PBI and their various approaches are outlined in Table S1. In general, its proton conductivity can be directly improved by increasing its PA doping level. For this purpose, researchers have utilized different methods to create a porous membrane structure and substantially improve PA uptake, such as by varying the sizes of porogens, which are removed after membrane fabrication [19-21], and membrane formation through gelation [22,23]. The use of dibutyl phthalate as the porogen for PBI has been widely studied as it offers convenient control over porosity and viability $[24,25]$. However, using porogens can create large pores that can cause severe corrosion damage and carbon monoxide poisoning due to PA bleeding-out or chemical degradation of the membrane in the PBI/acid complexes.

Non-solvent induced phase separation (NIPS) is a widely studied method for the synthesis of a porous PBI membrane. It has been applied to various polymers in the fields of nanofiltration, separation, and reverse osmosis [26-28]. In addition, NIPS yields larger pore structures than other available methods. It is also easily controllable and suitable for PBI and other applications [29-31]. Porous membranes synthesized via NIPS exhibit excellent acid uptake, which directly correlates to their proton conductivity. To the best of our knowledge, membranes synthesized via this method for a high-temperature fuel cell system using PA have not been reported thus far [32-34]. Initial testing indicated the extremely high uptake of PA, resulting in the dissolution of the membrane at high temperatures, similar to that in a solvent [22-35]. To overcome this, the membranes are cross-linked to improve their stability and significantly reduce their solubility [36-40]. However, several approaches for cross-linking are performed during the film casting phase, which may interfere with the NIPS process. Thus, the ideal thermal cross-linking method an appropriate approach to overcome membrane dissolution as it can be conducted after membrane fabrication [41-43].

In this work, we synthesize porous meta-PBI ( $m$-PBI) membranes via NIPS. The $m$-PBI was chosen over other candidates such as p-PBI, as their inherently reduced solubility hindered the porous membrane fabrication process. Chemical and morphological analyses of the synthesized membranes were conducted using Fourier transform infrared spectroscopy (FT-IR), thermogravimetric analysis (TGA), and scanning electron microscopy (SEM), in order to optimize and evaluate cross-linking and performance through interactions with PA. Moreover, PA doping and swelling were characterized via doping level testing. The performance of the membrane for application in HT-PEMFCs was evaluated based on proton conductivity using an Impedance Analyzer. Furthermore, membrane electrode assembly (MEA) was performed to determine the single cell performance of the membrane.

\section{Experimental}

\subsection{Materials}

For the synthesis of $m$-PBI, isophthalic acid (IPA) and polyphosphoric acid (PPA, 115\%) were purchased from Sigma Aldrich (St. Louis, MI, USA). Furthermore, 3,3'-diaminobenzidine (DAB) was 
purchased from TCI Chemicals (Tokyo, Japan). Sodium carbonate $\left(\mathrm{Na}_{2} \mathrm{CO}_{3}\right)$, dimethylacetamide (DMAc), acetone, and isopropyl alcohol were purchased from DUKSAN Chemical (Seoul, South Korea). Deionized (DI) water was obtained from a Milli-Q Ultrapure water purification system. For the acid doping of the membranes and the MEA fabrication, $\mathrm{PA}\left(85 \mathrm{wt} \%\right.$ in $\left.\mathrm{H}_{2} \mathrm{O}\right)$ was purchased from Sigma Aldrich. For MEA fabrication, polytetrafluoroethylene (PTFE, $60 \mathrm{wt} \%$ in $\mathrm{H}_{2} \mathrm{O}$ ) as the binder was purchased from Sigma Aldrich, and $\mathrm{Pt} / \mathrm{C}$ ( $40 \mathrm{wt} \%$ on carbon) was purchased from Alfa Aesar (Ward Hill, MA, USA). A carbon cloth (HT1400W, BASF) was used as the gas diffusion layer. All reagents used in this work were used as received without any further purifications.

\subsection{Synthesis of $m-P B I$}

The $m$-PBI was synthesized via the polycondensation method, which was reported by Kumbharkar et al. [35], with minor adjustments. The overall reaction is depicted in Figure 1A. In a three-neck flask with a mechanical stirrer, thermometer, and nitrogen inlet, DAB $(2.165 \mathrm{~g})$ was dissolved in PPA $(75 \mathrm{~g})$ at $120^{\circ} \mathrm{C}$. IPA $(1.678 \mathrm{~g})$ was then added to this solution, and the temperature was increased to $200^{\circ} \mathrm{C}$. The solution was stirred for $12 \mathrm{~h}$, during which its viscosity gradually increased with the synthesis time. The solution was subsequently poured into DI water and was consecutively washed until it was neutral. Thereafter, the precipitates were kept in $10 \%$ aqueous $\mathrm{Na}_{2} \mathrm{CO}_{3}$ solution for $12 \mathrm{~h}$ to remove any residual PPA within the polymer matrix. Finally, the precipitates were collected and dried in vacuum at $80^{\circ} \mathrm{C}$ for three days to remove any traces of water.<smiles>Nc1ccc(-c2ccc(N)c(N)c2)cc1N</smiles>

3,3 diaminobenzidine (DAB)

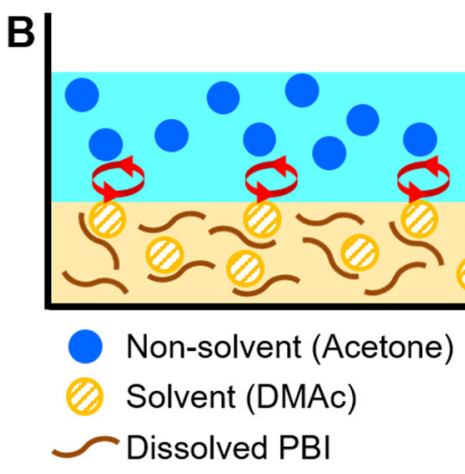<smiles>O=C(O)c1cccc(C(=O)O)c1</smiles>

Isophthalic acid (IPA)

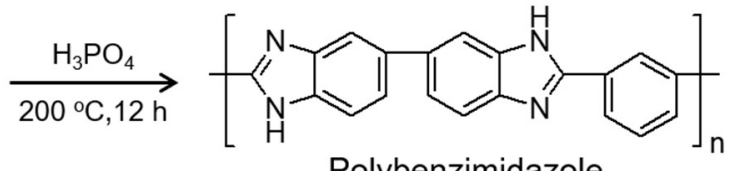

Polybenzimidazole (PBI)

Figure 1. (A) Synthesis of meta-polybenzimidazole ( $m$-PBI) and (B) the non-solvent induced phase separation mechanism to achieve porosity.

\subsection{Preparation of Highly Porous m-PBI Membranes}

The synthesized $m$-PBI powder was added to create a $10 \mathrm{wt} \%$ solution in DMAc, and the solution was stirred at $60^{\circ} \mathrm{C}$. After achieving a homogeneous solution, it was uniformly spread onto a glass plate using a spin coater. The cast solution was placed in acetone for $3 \mathrm{~h}$ to ensure maximum solvent exchange (Figure 1B). Subsequently, it was placed in vacuum for $8 \mathrm{~h}$ at $80^{\circ} \mathrm{C}$ to remove the acetone and residual solvent. It was then washed with DI water, peeled, and dried overnight to remove the residual water. This sample was heated to $350{ }^{\circ} \mathrm{C}$ in a ceramic oven for different amounts of time (up to $3 \mathrm{~h}$ ) before cooling to $25^{\circ} \mathrm{C}$. The samples were then labeled $m$-PBI350-x, where $\mathrm{x}$ denotes the duration of heating $(\mathrm{h})$ at $350^{\circ} \mathrm{C}$. As a reference, a non-porous $m$-PBI film was produced using DMAc without the phase inversion process and spread on a glass plate; the solvent was removed by placing this sample under vacuum at $80^{\circ} \mathrm{C}$ for $8 \mathrm{~h}$. All samples for the electrochemical analyses were doped with $85 \mathrm{wt} \%$ PA for 3 days at $60^{\circ} \mathrm{C}$ to achieve the maximum uptake. 


\subsection{Fabrication of PEM Fuel Cell MEA}

The catalyst solution was prepared by adding the desired amount of $\mathrm{Pt} / \mathrm{C}$ (46.7 wt\% Pt, Tanaka Kikinzoku Kogyo K.K, Chiyoda City, Japan) and PFTE in a water/isopropyl alcohol solution with a ratio of $4: 1 \mathrm{w} / \mathrm{w}$. To maintain good dispersion, the concentration of the catalyst/binder should be $\sim 1 \%$. The solution was then sonicated for $30 \mathrm{~min}$ to ensure even dispersion and sprayed onto gas diffusion layers using a spray gun, to create a gas diffusion electrode (GDE). The catalyst loading was $1.5 \mathrm{mg} \mathrm{Pt}$ $\mathrm{cm}^{-2}$ for both sides. Thereafter, the GDE was annealed at $350{ }^{\circ} \mathrm{C}$ for $10 \mathrm{~min}$. The prepared GDEs were used to sandwich the PA-doped membrane fitted with a gasket in a single fuel cell at $75 \mathrm{~N} \mathrm{~m}$ for MEA testing.

\subsection{Characterization}

The synthesis of the membrane was confirmed via FT-IR (VERTEX 70v, Bruker, Billerica, MA, USA), and its thermal stability was measured using TGA (Q50, TA Instrument, New Castle, DE, USA). The structure of the membrane was observed using SEM (JEOL-6701F, JEOL, Akishima, Japan) after Pt sputtering.

The porosity of the membranes was measured by method previously reported [44], where the membranes were immersed in $n$-butanol for $1 \mathrm{~h}$ and the weight of before and after immersing was recorded. The porosity was calculated via the following equation.

$$
\mathrm{P} \%=\frac{M_{\mathrm{B}} / \rho_{B}}{M_{\mathrm{PBI}} / \rho_{P B I}+M_{\mathrm{B}} / \rho_{B}}
$$

where $\mathrm{P} \%$ is porosity of the membrane, $M_{\mathrm{PBI}}$ the mass of $m$-PBI membrane, $M_{\mathrm{B}}$ the mass of absorbed $n$-butanol, $\rho_{\text {PBI }}$ the density of the membrane and $\rho_{\mathrm{B}}$ the density of $n$-butanol.

The membranes were dissolved in the selected solvent and heated at $80^{\circ} \mathrm{C}$ in DMAc and at $160^{\circ} \mathrm{C}$ in PA for a specific amount of time. The samples were washed with water and dried to remove the absorbed solvent. The solubility of the membranes was then determined by obtaining their gel content, as follows:

$$
\text { Gel content }(\mathrm{wt} \%)=100 *\left(\frac{w_{2}}{w_{1}}\right)
$$

where $w_{1}$ is the initial weight, and $w_{2}$ is weight after dissolution.

To calculate the doping level of the membranes, the amount of doped PA was estimated by weighing the membrane before and after doping. The initial weight of the membrane $\left(W_{d r y}\right)$ was recorded by drying in a vacuum oven at $80^{\circ} \mathrm{C}$. The membrane was then removed and weighed after wiping off excess PA $\left(W_{\text {wet }}\right)$. The doping level was calculated by

$$
\mathrm{ADL}=\frac{\left(\mathrm{W}_{w e t}-\mathrm{W}_{d r y}\right) / M_{P A}}{\mathrm{~W}_{d r y} / M_{P B I}}
$$

where ADL is the acid doping level, $M_{\mathrm{PA}}$ and $M_{\mathrm{PBI}}$ denote the molecular weights of PA and $m$-PBI repeat units, respectively.

Swelling ratio of the samples was also noted and calculated by

$$
\text { Swelling ratio }(\%)=100 * \frac{A_{\text {wet }} T_{\text {wet }}-A_{d r y} T_{d r y}}{A_{d r y} T_{d r y}}
$$

where $A$ is the area of the membrane, and $T$ is its thickness; wet and $d r y$ indicate the undoped and doped states, respectively.

The PA retention ability of the composite film was also investigated. An acid leaching test was performed, similar to that reported by Quartarone et al. [45]. The migration stability of the acid in the composite membranes was characterized by the PA weight loss $(R)$ in the membrane, which was 
obtained under a water vapor condition by hanging the membrane above boiling water for a certain period to allow the water drops to coalesce on the membrane surface. These membranes were then periodically removed and dried in order determine their weight $\left(W_{i}\right)$. The $R$ of PA from the membrane was calculated by

$$
\mathrm{R}=\frac{\mathrm{W}_{0}-\mathrm{W}_{i}}{\mathrm{~W}_{P A}} \times 100 \%
$$

where $W_{0}$ is the initial doped weight of the membrane, and $W_{P A}$ is the weight of the doped PA inside the membrane, calculated using Equation (5).

The proton conductivity of the PA-doped composite membranes was measured using electrochemical impedance spectroscopy with a frequency range of $0.1 \mathrm{~Hz}$ to $100 \mathrm{kHz}$. The four-probe test method was carried out using a potentiostat (Reference 600, Gamry) and a conductivity cell without humidification to calculate the resistance from Nyquist plot. Subsequently, the conductivity was calculated as follows:

$$
\text { Proton Condcutivity }(\mathrm{S} / \mathrm{cm})=\frac{d}{\Omega A}
$$

where $d$ is the distance between two electrodes, $\Omega$ is the resistance of the membrane, and $A$ is the cross-sectional area of the measured membrane. For temperature dependence of proton conductivity, membrane was kept at $160{ }^{\circ} \mathrm{C}$ prior to measurement to remove traces of water for more reliable measurement.

Based on linear regression, the activation energy was calculated using the proton conductivity of the membranes to plot the Arrhenius equation:

$$
\sigma=\sigma_{0} \exp \left[\frac{-\mathrm{E}_{a}}{\mathrm{RT}}\right]
$$

where $\sigma$ is the proton conductivity $\left(\mathrm{S} \mathrm{cm}^{-1}\right), \sigma_{0}$ is the pre-exponential factor $\left(\mathrm{S} \mathrm{K}^{-1} \mathrm{~cm}^{-1}\right), \mathrm{E}_{\mathrm{a}}$ is activation energy $\left(\mathrm{kJ} \mathrm{mol}^{-1}\right), R$ is the ideal gas constant $\left(\mathrm{J} \mathrm{mol}^{-1} \mathrm{~K}^{-1}\right)$, and $T$ is the absolute temperature expressed as 1000/K.

MEA was evaluated at $160{ }^{\circ} \mathrm{C}$ on porous $m$-PBI350-2 and non-porous $m$-PBI membranes in a single cell using a cell station (SMART2, WonATech, Seoul, South Korea). The active area was $1 \mathrm{~cm}^{2}$, $\mathrm{Pt}$ loading was $1.5 \mathrm{mg} \mathrm{cm}^{-2}$, and the flow rates of $\mathrm{H}_{2}$ and $\mathrm{O}_{2}$ were $100 \mathrm{ccm}$. They were activated with a current load of $200 \mathrm{~mA} \mathrm{~cm}^{-2}$ prior to the measurement.

\section{Results and Discussion}

FT-IR was used to observe the synthesis of the $m$-PBI membranes and the chemical changes caused by the phase inversion and thermal curing. Figure 2A shows the FT-IR spectra of the prepared membranes. There are no noticeable peaks around the $1700 \mathrm{~cm}^{-1}$ region, which corresponds to the $\mathrm{C}=\mathrm{O}$ stretch of carbonyl groups; thus, almost all of these groups participated in the formation of benzimidazole rings. The absorption of the $\mathrm{N}-\mathrm{H}$ group and aromatic $\mathrm{C}-\mathrm{C}$ stretching was observed at $1280 \mathrm{~cm}^{-1}$ and $1440 \mathrm{~cm}^{-1}$, respectively. $\mathrm{C}=\mathrm{C} / \mathrm{C}=\mathrm{N}$ stretching was observed at $1610 \mathrm{~cm}^{-1}$. These results are in good agreement with existing literature on the successful synthesis of $m$-PBI membranes [46]. In addition, there are no significant differences between the species, confirming that the NIPS process was not hampered by their chemical structures.

As $m$-PBI is known for its excellent thermal stability, the effect of the NIPS process and thermal curing on this property was studied via TGA, as shown in Figure 2B. Non-porous $m$-PBI are relatively stable up to $500{ }^{\circ} \mathrm{C}$, which is significantly higher than their operating temperatures in fuel cells. The initial weight loss, which begins at approximately $100^{\circ} \mathrm{C}$, is attributed to the release of absorbed water and/or any residual solvent [8,9]. At higher temperatures of approximately $600^{\circ} \mathrm{C}$, the degradation of the main $m$-PBI backbone can be observed, showing typical temperature profile of aromatic PBI [47]. There are no other noticeable peaks, and the thermal treatment did not alter the thermal profile of the membranes. The phased inversion-induced freestanding $m$-PBI membranes could also maintain 
their original shapes without cracking after releasing the applied bending, twisting, and folding forces (Figure 2C).
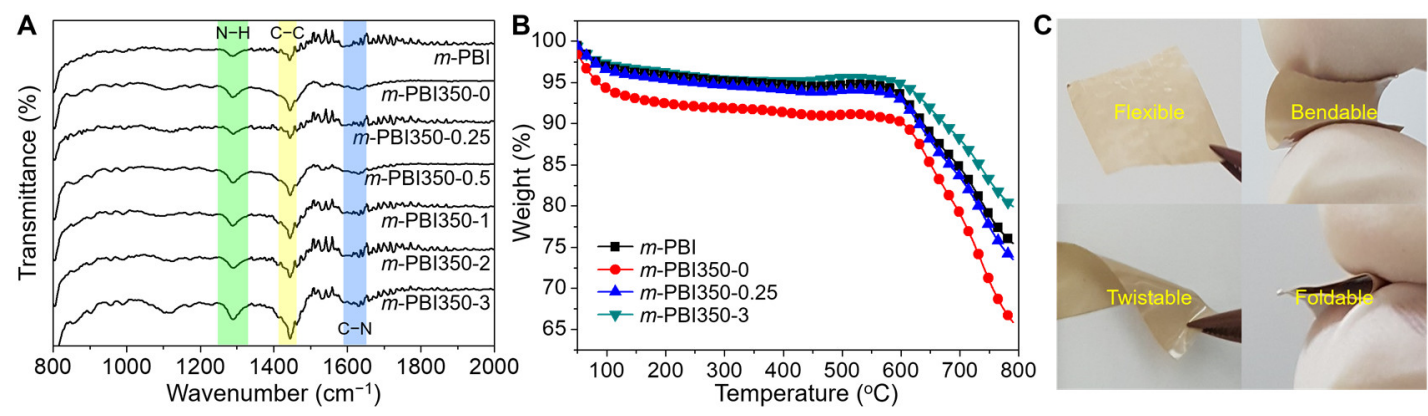

Figure 2. (A) Fourier transform infrared spectra and (B) thermogravimetric analysis of non-porous $m$-PBI and $m$-PBI350-x membranes. (C) Demonstration of the robustness of the freestanding $m$-PBI350-2.

In order to determine the porosity of the membranes, an $n$-butanol adsorption test was carried out (Figure 3A). It was seen that the membranes synthesized via NIPS method all had a porosity of around $60 \%$. The porosity also decreased with increased thermal treatment, possibly due to densification from crosslinking. However, the degree in which the thermal treatment affects the porosity is negligible and should not affect the acid uptake properties. The surfaces of the membranes were subjected to SEM, and their cross sections were obtained to observe the morphological structures and successful phase inversion of $m$-PBI membranes. As shown in Figure 3A-F, a highly porous structure is achieved for all phase-inversed membranes with the distribution of both large and small pores. The middle section exhibits pillar-like macroporous structures. On magnifying the walls, highly porous layers are observed. In addition, filling up all these pores may reduce the amount of gas cross-over, which is a major concern of MEA tests in HT-PEMFCs as it could lead to severe gas cross-over that decreases its performance and durability or causes immediate failure upon initial testing [48]. As observed in the cross-section, the surface of the membrane does not exhibit any large pore openings. The surface images indicate the presence of underlying closed pores, which is confirmed by magnifying the surfaces with a negligible amount of pores (Figure 3D-E). This is beneficial for a fuel cell membrane as it reduces the gas cross-over. Moreover, an asymmetric membrane is derived via the NIPS process. There are no significant differences in the morphology of the neat and thermally cured porous samples. This was confirmed from porosity measurement, where it was seen that porosity somewhat decreased with increased thermal treatment, and the variances were negligible. During the acid doping test, partial dissolution was observed for the samples with low curing time at elevated temperatures $\left(>80^{\circ} \mathrm{C}\right)$, where the membrane became visibly semi-transparent and some dopant leached out upon heating. This suggests that the pores collapsed due to the partial dissolution and insufficient cross-linking of the membrane (Figure 3F). The cross-section of the membrane was investigated after the removal of PA. The images confirm the collapse of the pores. In addition, the membrane was permanently deformed and became extremely brittle after drying, making it unsuitable for HT-PEMFCs. Thus, a sufficient curing time is necessary for the HT-PEMFC environment.

To determine the decreased solubility from the thermal cross-linking of the phase-inversed membrane for HT-PEMFCs, the solubility of the membranes was measured in DMAc at $80{ }^{\circ} \mathrm{C}$ and PA at $160{ }^{\circ} \mathrm{C}$. Previous studies indicated a drastic reduction in the solubility of membranes thermally treated at $350^{\circ} \mathrm{C}$ in DMAc and PA [41,49]. From Figure 3F,G, it is evident that there is insufficient thermal treatment of the membranes, resulting in partial dissolution and the collapse of pores. In DMAc, both $m$-PBI350-0 and $m$-PBI splintered within an hour and fully dissolved by the end of the test (Figure 4A). The $m$-PBI350-0.25 was dissolved partially, rendering it permanently morphed. Notably, $m$-PBI350-2 did not exhibit solubility in DMAc. In PA, none of the samples dissolved after $1 \mathrm{~h}$; however, a majority of them dissolved by the end of the test (Figure 4B). The $m$-PBI350-0 dissolved faster than $m$-PBI, which was likely due to its porosity, which led to greater contact with 
the solvent. The $m$-PBI350-0.25 turned into a gelatinous goop and did not retain any of its original shape. Even $m$-PBI350-2 exhibited some dissolution with slight changes in weight and discoloration of the solution. Generally, the $m$-PBI350-2 sample exhibited exceptional resistance to solvents, while the lesser cured membranes exhibited improved resistance compared to the non-cured $m$-PBI, thereby indicating successful cross linkage.
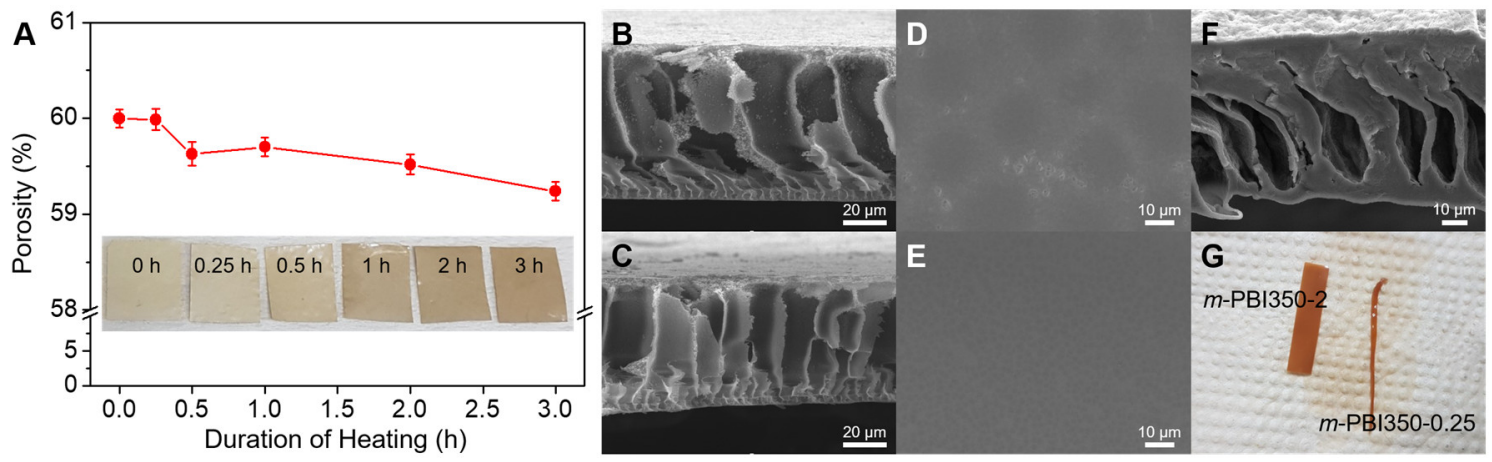

Figure 3. (A) $n$-Butanol adsorption porosity (\%) values of $m$-PBI350-x membranes with respect to duration of heating time at $350{ }^{\circ} \mathrm{C}$ (inset: digital camera photographs of $m$-PBI350-x membranes). Scanning electron microscopy images of the cross-section of (B) $m$-PBI350-0 and (C) $m$-PBI350-3; and the membrane surface of (D) $m$-PBI350-3 glass side and (E) air side. (F) Cross-section of $m$-PBI350-0.25 and (G) image of the membrane after acid removal.
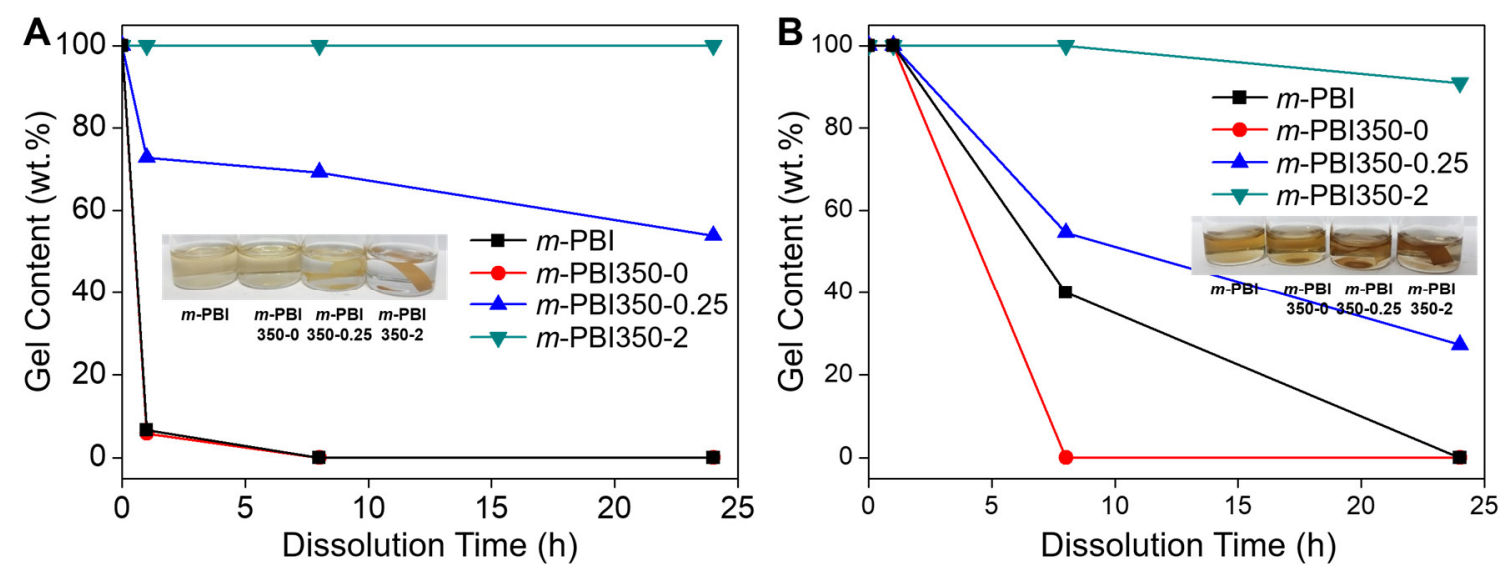

Figure 4. Solubility with respect to time in (A) dimethylacetamide (DMAc) $\left(80^{\circ} \mathrm{C}\right)$ and $(\mathbf{B})$ phosphoric acid $(\mathrm{PA})\left(160^{\circ} \mathrm{C}\right)$. The inset images were captured after testing for $24 \mathrm{~h}$.

The doping levels and swelling ratio of the membranes were evaluated and are presented in Table 1. Controlling the swelling ratio is essential because a higher membrane thickness directly leads to increased ohmic resistance in the cell. The thermal treatment of membranes drastically suppresses their swelling behavior. For the uncured phase-inversed membrane ( $m$-PBI350-0), extreme swelling was observed with swelling in the planar direction and an increased thickness more than twice the original value; however, these changes in the other samples were negligible or absent. For $m$-PBI350-2 and $m$-PBI350-3, prolonged thermal treatment gradually decreased the swelling ratio of the membranes until it stabilized. $m$-PBI350-1, $m$-PBI30-2, and $m$-PBI350-3 showed swelling ratio lower than that of $\mathrm{m}$-PBI. However, semi-brittleness was also noted for $m$-PBI350-3 and above.

For all porous samples, the ADL of the membranes is higher than that of $m$-PBI, which is comparable to the ADL of direct synthesized samples [22,23,50]. Even with decreased doping levels, the ADL of the treated samples still exceeds that of normal $m$-PBI. Longer thermal treatment resulted in reduced acid uptake. Thus, it can be assumed that an increased degree of cross-linking leads to a more 
densely packed polymer matrix, thereby suppressing membrane swelling and reducing maximum acid uptake. Thus, the curing time should be optimized such that maximum performance is achieved.

Table 1. Swelling ratio and PA doping level of $m$-PBI350-x membranes.

\begin{tabular}{ccccc}
\hline Sample & $\begin{array}{c}\text { Initial Thickness } \\
(\boldsymbol{\mu} \mathbf{m})\end{array}$ & $\begin{array}{c}\text { Doped Thickness } \\
(\boldsymbol{\mu \mathbf { m } )}\end{array}$ & $\begin{array}{c}\text { Swelling Ratio } \\
(\boldsymbol{\%})\end{array}$ & $\begin{array}{c}\text { Acid Doping } \\
\text { Level (ADL) }\end{array}$ \\
\hline$m$-PBI350-0 & 65 & 155 & 241 & 51.5 \\
$m$-PBI350-0.25 & 64 & 113 & 77.2 & 50.4 \\
$m$-PBI350-0.5 & 63 & 101 & 64.32 & 44.7 \\
$m$-PBI350-1 & 62 & 91 & 43.5 & 38.0 \\
$m$-PBI350-2 & 62 & 86 & 38.7 & 33.8 \\
$m$-PBI350-3 & 62 & 85 & 37.1 & 29.9 \\
$m-$ PBI & 49 & 72 & 50.6 & 11.0 \\
\hline
\end{tabular}

Proton conductivity is one of the key parameters in determining the performance of proton exchange membranes. Figure 5A depicts the proton conductivity of the samples with respect to time. The transport mechanism within the membrane is attributed to the Grotthus mechanism (i.e., protons hop through the network of hydrogen bonds) and vehicle mechanism (i.e., protons bound to the acid molecule move through the membrane) [51,52]. The porous nature of the membranes significantly increases the amount of free acid for operation in the system and improves proton conductivity. The $m$-PBI350-0 and $m$-PBI350-0.25 were not tested due to their instability at elevated temperatures. All the samples with longer treatment times than $m$-PBI350-0.5 exhibited excellent proton conductivities, as compared to $m$-PBI. A majority of the samples exhibit high proton conductivities with minimal differences; $m$-PBI350-2 achieved a conductivity of $0.194 \mathrm{~S} \mathrm{~cm}^{-1}$ at $160{ }^{\circ} \mathrm{C}$. Above a certain doping level, it can be assumed that the amount of free acid in the matrix has little impact in further increasing the proton conductivity of the membranes. However, the proton conductivity of $m$-PBI350-3 is lower; this could be attributed to its lower acid retention ability and brittleness, which can cause a loss of acid during stabilization.
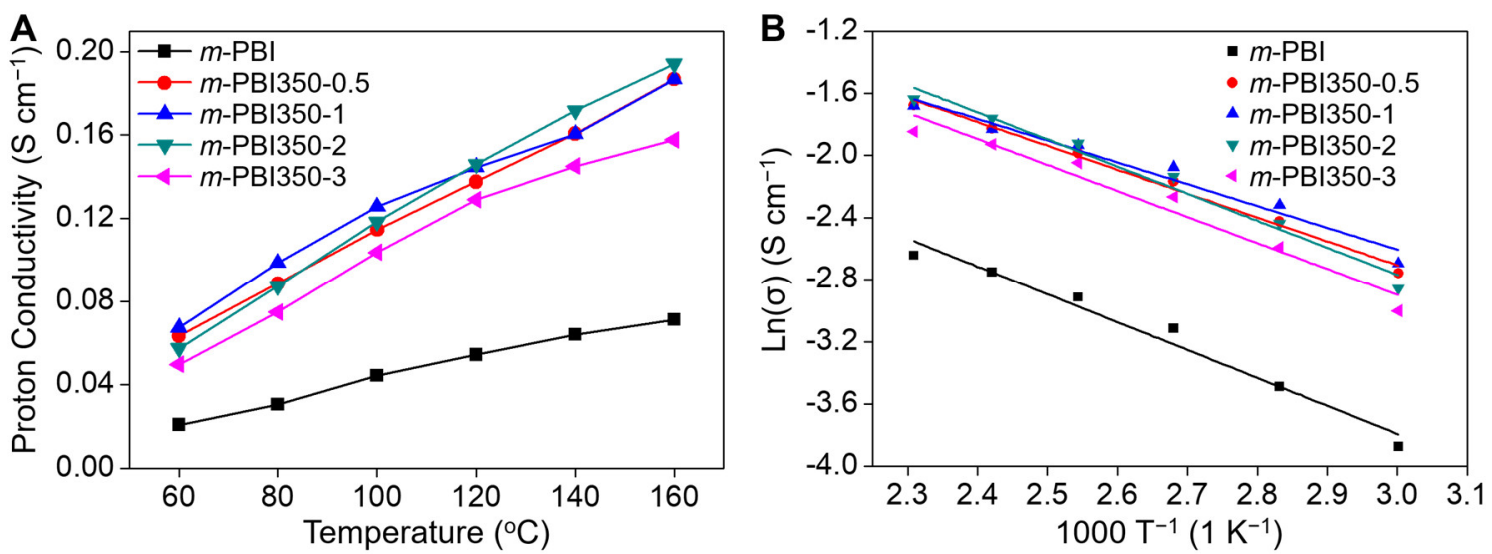

Figure 5. (A) Proton conductivity with respect to temperature and (B) Arrhenius plot for the proton conductivity of the phosphoric acid-doped membranes.

From Figure 5A, it can be seen that the conductivity of the membranes increases with temperature. Hence, an increase in temperature enables more favorable dynamics for both proton transfer and structural reorganization, thereby increasing the performance of the membranes, as reflected in Figure 5B. Considering this, their activation energy can be calculated using the Arrhenius equation (Equation (7)). Figure 5B presents typical Arrhenius plots obtained by plotting the proton conductivity of different membranes against the inverse of absolute temperature. The activation energy of the samples, which lies between $11.6 \mathrm{~kJ} \mathrm{~mol}^{-1}$ and $14.5 \mathrm{~kJ} \mathrm{~mol}^{-1}$, were calculated using the slopes of these 
plots. The data fit well with the theoretical values, suggesting that Grotthus mechanism is the primary pathway for the proton conduction process. The lower activation energy can be attributed to the presence of abundant free PA species in the membrane and their involvement in the transport process, as confirmed by the vast amount of free acid in the porous polymer matrix. Moreover, due to the porous morphology of the membrane, protons may move more easily, resulting in lower conduction activation energy [18].

Unlike Nafion ${ }^{\circledR}$-based systems, which require external humidification, anhydrous fuel cell systems using PA as the medium cannot reobtain the acid once it leaches out. Furthermore, under prolonged operations, PA losses may occur due to the formation of water at the cathode end. Thus, PA retention ability is vital in maintaining the performance of PEM.

Acid retention was tested to observe the effect of the porous structure of the membrane on its acid-trapping ability. The samples were subjected to water vapor at $100^{\circ} \mathrm{C}$, where water was allowed to coalesce and drop down on the surface of the membrane. During the course of the testing, the PA doping level for all membranes decreased constantly. Through testing for an extended period of time ( $48 \mathrm{~h}$ ), PA was completely removed from the membranes. The obtained acid loss ratios are presented in Figure 6A. It was observed that all porous $m$-PBI samples exhibit delayed acid losses. However, for $m$-PBI350-0 and $m$-PBI350-0.25, the loss ratio converged to that of $m$-PBI after $8 \mathrm{~h}$ of testing. For higher cross-linked samples, the loss ratio was lower than that of $m$-PBI, indicating that a higher degree of cross-linking leads to a tighter binding of PA on the membrane. Furthermore, a curing time of $0.5-2 \mathrm{~h}$ yields the highest retention ability. Escorihuela et al. [53] have previously demonstrated that PA leaching is prominent after a few cycles, thus a similar approach was employed to observe PA leaching behavior. The membrane was subjected to few cycles where the temperature was raised from $20^{\circ} \mathrm{C}$ to $160^{\circ} \mathrm{C}$ (first ramp) and $160^{\circ} \mathrm{C}$ to $20^{\circ} \mathrm{C}$ (second ramp) and repeated once more (Figure S1). The trend was the same as reported previously, wherein the first ramp showed high conductivity even at a lower temperature and the results after the first ramp show better correlation with temperature. This is possibly due to existence of water in the membrane and excess acid at the surface, which can contribute to proton conductivity but is quickly lost upon heating. The loss rate of $m$-PBI350-2 was lesser than that of $m$-PBI, but decreased nonetheless.
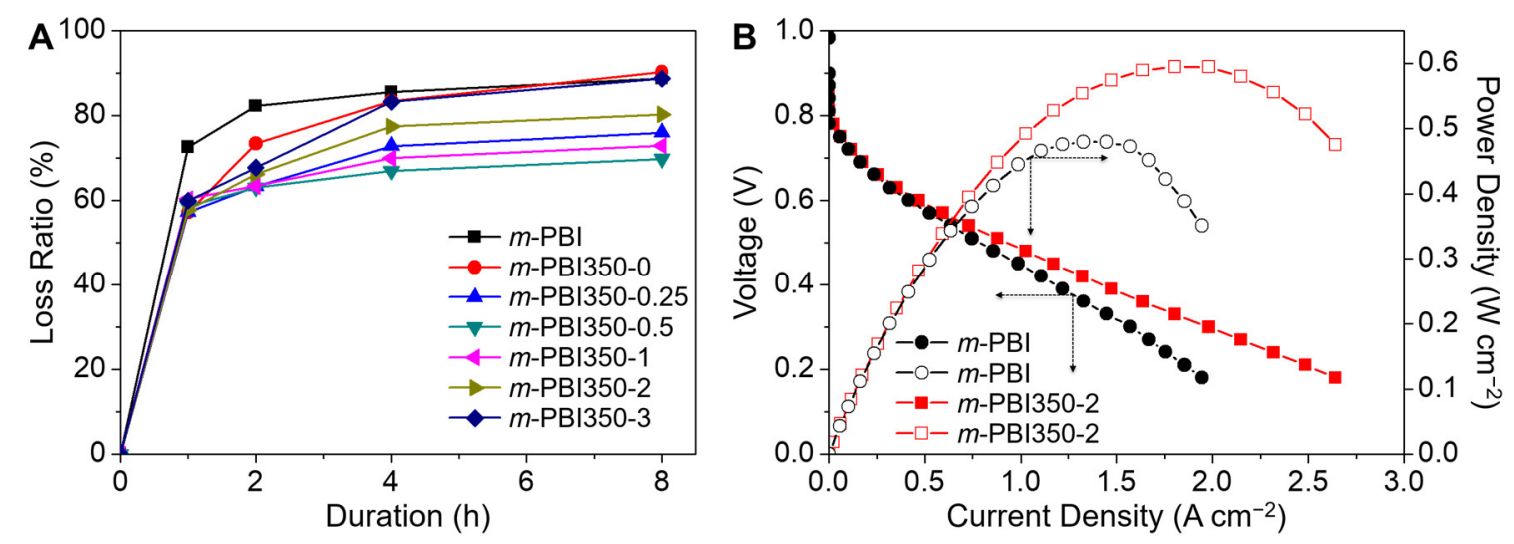

Figure 6. (A) Phosphoric acid retention of the membranes with respect to time. (B) Fuel cell performances in terms of power density and voltage with respect to the current density of $m$-PBI and $m$-PBI350-2.

The polarization curves were measured using a single cell test at $160{ }^{\circ} \mathrm{C}$ with $\mathrm{H}_{2}$ and $\mathrm{O}_{2}$, without any external humidification (Figure $6 \mathrm{~B}$ ). The test was conducted using the $m$-PBI350-2 membrane, which exhibited the best performance in terms of proton conductivity and swelling behavior. The denser layer faced the cathode side, though its effect was not significant in previous study [54]. Low open circuit voltages are observed for $m$-PBI350-2 [55]. In addition, compared to $m$-PBI, $m$-PBI350-2 exhibited better performance with a maximum power density of $595 \mathrm{~mW} \mathrm{~cm}^{-2}$, even when considering membrane 
thickness. It also exhibited a stable performance without any apparent decline, which is commonly observed for damaged membranes with high cross-over [5,8,9], indicating the asymmetric nature of the membrane surface and the sufficient pores filled with liquid PA to warrant minimal gas cross-over (Figure 7A).
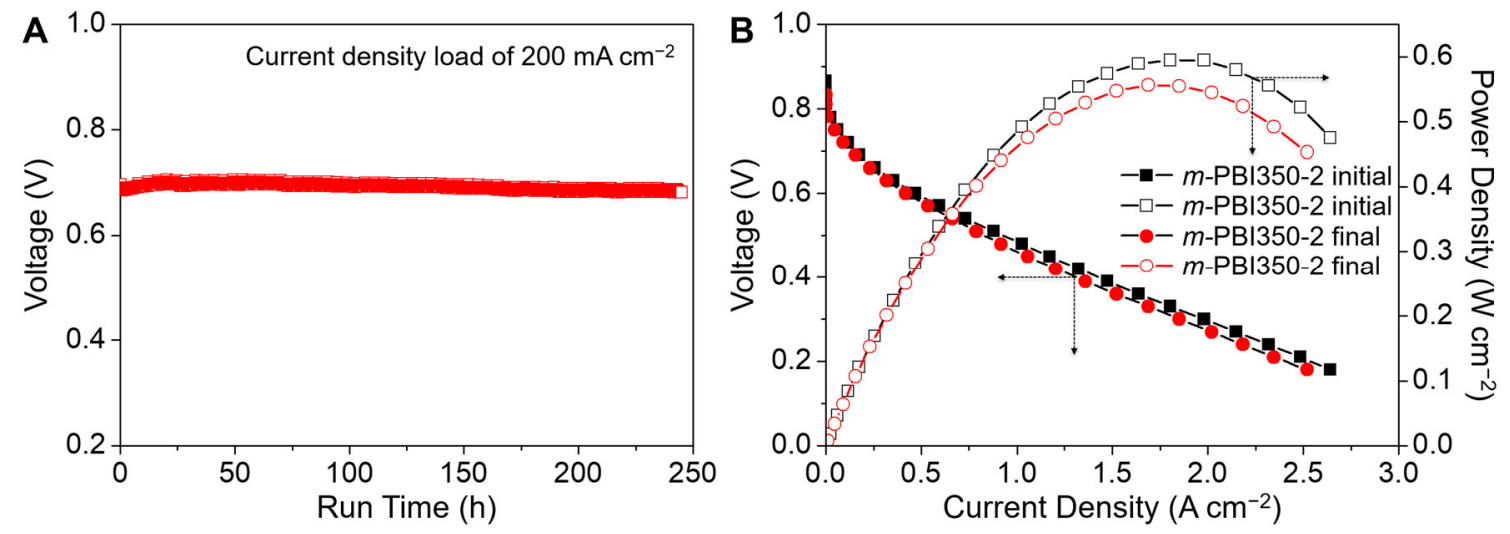

Figure 7. (A) Fuel cell performance of $m$-PBI350-2 with respect to time at a constant current density.

(B) Cell performances before and after the durability test.

As $m$-PBI350-2 achieved a stable performance, the durability of the membrane was also tested (Figure 7B). The long-term durability loss of $m-\mathrm{PBI}$ is attributed to acid leaching [56], which is more extensive for a porous membrane than dense $m$-PBI because there is an excessive amount of free acid. The cell was placed under a current load of $200 \mathrm{~mA} \mathrm{~cm}^{-2}$, and a full polarization curve was obtained every $4 \mathrm{~h}$. Moreover, the voltage was monitored constantly. After a run time of $\sim 250 \mathrm{~h}$, the cell voltage decreased from $0.705 \mathrm{~V}$ to $0.686 \mathrm{~V}$ when operated under $200 \mathrm{~mA} \mathrm{~cm}^{-2}$ (loss rate: $77.5 \mu \mathrm{V} \mathrm{h}^{-1}$ ). Although porous membranes feature lower durability than dense $m$-PBI [55], the leaching of free acid was minimized, similar to the acid retention ability.

\section{Conclusions}

Highly porous $m$-PBI membranes were successfully synthesized via phase inversion and employed in the HT-PEMFC environment using thermal cross-linking. The completion of the synthesis was confirmed based on FT-IR, TGA, and SEM. The porous $m$-PBI membranes were subjected to different thermal treatment conditions, yielding varying performances. SEM was used to investigate the porous nature and effect of thermal cross-linking on the morphology of the membranes. The amount of PA uptake was calculated, indicating improvements in swelling ratio and retention ability; however, the doping level was found to decrease upon an increase in the thermal treatment. The proton conductivities of $m$-PBI350-0.5 and membranes with longer treatment times increased; the maximum conductivity $\left(0.194 \mathrm{~S} \mathrm{~cm}^{-1}\right.$ ) was obtained using $m$-PBI350-2 and the minimum conductivity was $0.158 \mathrm{~S} \mathrm{~cm}^{-1}$, both of which are higher than that of $m$-PBI. The maximum power density was noted to be $595 \mathrm{~mW} \mathrm{~cm}^{-2}$ for $m$-PBI350-2. The results of $m$-PBI350-3 suggest that prolonged heat treatment can result in performance loss, whereas those of $m$-PBI350-0.25 indicated the necessity for sufficient cross-linking in HT-PEMFCs. Thus, it is important to optimize the curing time such that a maximum performance balance is achieved. The improved performance, compared to neat $m$-PBI, suggests that the proposed membranes are suitable electrolytes for HT-PEMFC systems. Moreover, future research is required for the optimization of pore size control in order to potentially improve membrane performance.

Supplementary Materials: The following are available online at http://www.mdpi.com/2073-4360/12/7/1604/s1, Figure S1: Proton conductivity of the m-PBI350-2 membranes during four consecutive temperature cycles, Table S1: Comparison of proton conductivity of PBI based membranes. 
Author Contributions: S.L. conceived and designed the experiment, synthesized the materials. S.L. and K.-H.N. wrote the manuscript. K.S. and G.K. assisted with the data analysis. K.-H.N. and H.H. supervised the entire study. All authors have read and agreed to the published version of the manuscript.

Funding: We acknowledge the financial support from Basic Science Research Program through the National Research Foundation (NRF) funded by the Ministry of Education [grant number NRF-2020R1A2C1009854]. It was also partially supported by Technology Development Program to Solve Climate Changes of The National Research Foundation (NRF) funded by the Ministry of Science, ICT \& Future Planning [grant number NRF-2015M1A2A2056833].

Conflicts of Interest: The authors declare no conflict of interest.

\section{References}

1. Bose, S.; Kuila, T.; Nguyen, T.X.H.; Kim, N.H.; Lau, K.-T.; Lee, J.H. Polymer membranes for high temperature proton exchange membrane fuel cell: Recent advances and challenges. Prog. Polym. Sci. 2011, 36, 813-843. [CrossRef]

2. Raja Rafidah, R.S.; Rashmi, W.; Khalid, M.; Wong, W.Y.; Priyanka, J. Recent Progress in the Development of Aromatic Polymer-Based Proton Exchange Membranes for Fuel Cell Applications. Polymers 2020, 12, 1061. [CrossRef]

3. Li, Q.; He, R.; Jensen, J.O.; Bjerrum, N.J. Approaches and Recent Development of Polymer Electrolyte Membranes for Fuel Cells Operating above $100^{\circ} \mathrm{C}$. Chem. Mater. 2003, 15, 4896-4915. [CrossRef]

4. Chandan, A.; Hattenberger, M.; El-kharouf, A.; Du, S.; Dhir, A.; Self, V.; Pollet, B.G.; Ingram, A.; Bujalski, W. High temperature (HT) polymer electrolyte membrane fuel cells (PEMFC)—A review. J. Power Sources 2013, 231, 264-278. [CrossRef]

5. Lee, S.; Seo, K.; Ghorpade, R.V.; Nam, K.H.; Han, H. High Temperature Anhydrous Proton Exchange Membranes Based on Chemically-Functionalized Titanium/Polybenzimidazole Composites for Fuel Cells. Mater. Lett. 2020, 263, 127167. [CrossRef]

6. Zeis, R. Materials and characterization techniques for high-temperature polymer electrolyte membrane fuel cells. Beilstein J. Nanotechnol. 2015, 6, 68-83. [CrossRef] [PubMed]

7. Shao, Y.; Yin, G.; Wang, Z.; Gao, Y. Proton exchange membrane fuel cell from low temperature to high temperature: Material challenges. J. Power Sources 2007, 167, 235-242. [CrossRef]

8. Seo, K.; Nam, K.H.; Han, H. Proton Transport in Aluminum-Substituted Mesoporous Silica Channel-Embedded High-Temperature Anhydrous Proton-Exchange Membrane Fuel Cells. Sci. Rep. 2020, 10, 10352. [CrossRef]

9. Seo, K.; Seo, J.; Nam, K.-H.; Han, H. Polybenzimidazole/inorganic composite membrane with advanced performance for high temperature polymer electrolyte membrane fuel cells. Polym. Compos. 2017, 38, 87-95. [CrossRef]

10. Escorihuela, J.; Garcia-Bernabe, A.; Montero, A.; Sahuquillo, O.; Gimenez, E.; Compan, V. Ionic Liquid Composite Polybenzimidazol Membranes for High Temperature PEMFC Applications. Polymers 2019, 11, 732. [CrossRef]

11. Rosli, R.E.; Sulong, A.B.; Daud, W.R.W.; Zulkifley, M.A.; Husaini, T.; Rosli, M.I.; Majlan, E.H.; Haque, M.A. A review of high-temperature proton exchangemembrane fuel cell (HT-PEMFC) system. Int. J. hydrogen Energy 2017, 42, 9293-9314. [CrossRef]

12. Haque, M.A.; Sulong, A.B.; Loh, K.S.; Majlan, E.H.; Husaini, T.; Rosli, R.E. Acid doped polybenzimidazoles based membrane electrode assembly for high temperature proton exchange membrane fuel cell: A review. Int. J. hydrogen Energy 2017, 42, 9156-9179. [CrossRef]

13. Araya, S.S.; Zhou, F.; Liso, V.; Sahlin, S.L.; Vang, J.R.; Thomas, S.; Gao, X.; Jeppesen, C.; Kær, S.K. A comprehensive review of PBI-based high temperature PEM fuel cells. Int. J. hydrogen Energy 2016, 41, 21310-21344. [CrossRef]

14. Escorihuela, J.; Sahuquillo, O.; Garcia-Bernabe, A.; Gimenez, E.; Compan, V. Phosphoric Acid Doped Polybenzimidazole (PBI)/Zeolitic Imidazolate Framework Composite Membranes with Significantly Enhanced Proton Conductivity under Low Humidity Conditions. Nanomaterials 2018, 8, 775. [CrossRef]

15. Uregen, N.; Pehlivanoglu, K.; Ozdemir, Y.; Devrim, Y. Development of polybenzimidazole/graphene oxide composite membranes for high temperature PEM fuel cells. Int. J. hydrogen Energy 2017, 42, 2636-2647. [CrossRef] 
16. Singh, B.; Devi, N.; Srivastava, A.K.; Singh, R.K.; Song, S.-J.; Krishnan, N.N.; Konovalova, A.; Henkensmeier, D. High temperature polymer electrolyte membrane fuel cells with Polybenzimidazole-Ce0.9Gd0.1P2O7 and polybenzimidazole-Ce0.9Gd0.1P2O7-graphite oxide composite electrolytes. J. Power Sources 2018, 401, 149-157. [CrossRef]

17. Plackett, D.; Siu, A.; Li, Q.; Pan, C.; Jensen, J.O.; Nielson, S.F.; Permyakova, A.A.; Bjerrum, N.J. High-temperature proton exchange membranes based on polybenzimidazole and clay composites for fuel cells. J. Mem. Sci. 2011, 383, 78-87. [CrossRef]

18. Hooshyari, K.; Javanbakht, M.; Shabanikia, A.; Enhessari, M. Fabrication $\mathrm{BaZrO}_{3} / \mathrm{PBI}$-based nanocomposite as a new proton conducting membrane for high temperature proton exchange membrane fuel cells. J. Power Sources 2015, 276, 62-72. [CrossRef]

19. Mecerreyes, D.; Grande, H.; Miguel, O.; Ochoteco, E.; Marcilla, R.; Cantero, I. Porous Polybenzimidazole Membranes Doped with Phosphoric Acid: Highly Proton-Conducting Solid Electrolytes. Chem. Mater. 2004, 16, 604-607. [CrossRef]

20. Zarrin, H.; Jiang, G.; Lam, G.Y.Y.; Fowler, M.; Chen, Z. High performance porous polybenzimidazole membrane for alkaline fuel cells. Int. J. hydrogen Energy 2014, 39, 18405-18415. [CrossRef]

21. Barati, S.; Abdollahi, M.; Mehdipourghazi, M.; Khoshandam, B. High temperature proton exchange porous membranes based on polybenzimidazole/lignosulfonate blends: Preparation, morphology and physical and proton conductivity properties. Int. J. hydrogen Energy 2019, 44, 30440-30453. [CrossRef]

22. Sannigrahi, A.; Arunbabu, D.; Jana, T. Thermoreversible Gelation of Polybenzimidazole in Phosphoric Acid. Macromol. Rapid Commun. 2006, 27, 1962-1967. [CrossRef]

23. Sannigrahi, A.; Ghosh, S.; Maity, S.; Jana, T. Polybenzimidazole gel membrane for the use in fuel cell. Polymer 2011, 52, 4319-4330. [CrossRef]

24. Shen, C.-H.; Jheng, L.-C.; Hsu, S.L.-C.; Wang, J.T.-W. Phosphoric acid-doped cross-linked porous polybenzimidazole membranes for proton exchange membrane fuel cells. J. Mater. Chem. 2011, 21, 15660-15665. [CrossRef]

25. Zeng, L.; Zhao, T.S.; An, L.; Zhao, G.; Yan, X.H. A high-performance sandwiched-porous polybenzimidazole membrane with enhanced alkaline retention for anion exchange membrane fuel cells. Energy Environ. Sci. 2015, 8, 2768-2774. [CrossRef]

26. Guillen, G.R.; Pan, Y.; Li, M.; Hoek, E.M.V. Preparation and Characterization of Membranes Formed by Nonsolvent Induced Phase Separation: A Review. Ind. Eng. Chem. Res. 2011, 50, 3798-3817. [CrossRef]

27. Wang, D.-M.; Lai, J.-Y. Recent advances in preparation and morphology control of polymeric membranes formed by nonsolvent induced phase separation. Curr. Opin. Chem. Eng. 2013, 2, 229-237. [CrossRef]

28. Ulbricht, M. Advanced functional polymer membranes. Polymer 2006, 47, 2217-2262. [CrossRef]

29. Valtcheva, I.B.; Marchetti, P.; Livingston, A.G. Crosslinked polybenzimidazole membranes for organic solvent nanofiltration (OSN): Analysis of crosslinking reaction mechanism and effects of reaction parameters. J. Mem. Sci. 2015, 493, 568-579. [CrossRef]

30. Wang, K.Y.; Xiao, Y.; Chung, T.-S. Chemically modified polybenzimidazole nanofiltration membrane for the separation of electrolytes and cephalexin. Chem. Eng. Sci. 2006, 61, 5807-5817. [CrossRef]

31. Valtcheva, I.B.; Kumbharkar, S.C.; Kim, J.F.; Bhole, Y.; Livingston, A.G. Beyond polyimide: Crosslinked polybenzimidazole membranes for organic solvent nanofiltration (OSN) in harsh environments. J. Mem. Sci. 2014, 457, 62-72. [CrossRef]

32. Chen, D.; Yu, S.; Liu, X.; Li, X. Porous polybenzimidazole membranes with excellent chemicalstability and ion conductivity for direct borohydride fuel cells. J. Power Sources 2015, 282, 323-327. [CrossRef]

33. Luo, T.; David, O.; Gendel, Y.; Wessling, M. Porous poly (benzimidazole) membrane for all vanadium redox flow battery. J. Power Sources 2016, 312, 45-54. [CrossRef]

34. van de Ven, E.; Chairuna, A.; Merle, G.; Benito, S.P.; Borneman, Z.; Nijmeijer, K. Ionic liquid doped polybenzimidazole membranes for high temperature Proton Exchange Membrane fuel cell applications. J. Power Sources 2013, 222, 202-209. [CrossRef]

35. Kumbharkar, S.C.; Islam, M.N.; Potrekar, R.A.; Kharul, U.K. Variation in acid moiety of polybenzimidazoles: Investigation of physico-chemical properties towards their applicability as proton exchange and gas separation membrane materials. Polymer 2009, 50, 1403-1413. [CrossRef] 
36. Yang, J.; Jiang, H.; Gao, L.; Wang, J.; Xu, Y.; He, R. Fabrication of crosslinked polybenzimidazole membranes by trifunctional crosslinkers for high temperature proton exchange membrane fuel cells. Int. J. hydrogen Energy 2018, 43, 3299-3307. [CrossRef]

37. Aili, D.; Li, Q.; Christensen, E.; Jensen, J.O.; Bjerrum, N.J. Crosslinking of polybenzimidazole membranes by divinylsulfone post-treatment for high-temperature proton exchange membrane fuel cell applications. Polym. Int. 2011, 60, 1201-1207. [CrossRef]

38. Choi, S.-W.; Park, J.O.; Pak, C.; Choi, K.H.; Lee, J.-C.; Chang, H. Design and Synthesis of Cross-Linked Copolymer Membranes Based on Poly(benzoxazine) and Polybenzimidazole and Their Application to an Electrolyte Membrane for a High-Temperature PEM Fuel Cell. Polymers 2013, 5, 77-111. [CrossRef]

39. Kerres, J. Blended and Cross-Linked Ionomer membranes for Application in Membrane Fuel Cell. Fuel Cells 2005, 5, 230-247. [CrossRef]

40. Gao, C.; Hu, M.; Wang, L.; Wang, L. Synthesis and Properties of Phosphoric-Acid-Doped Polybenzimidazole with Hyperbranched Cross-Linkers Decorated with Imidazolium Groups as High-Temperature Proton Exchange Membranes. Polymers 2020, 15, 515. [CrossRef]

41. Aili, D.; Cleemann, L.N.; Li, Q.; Jensen, J.O.; Christensen, E.; Bjerrum, N.J. Thermal curing of PBI membranes for high temperature PEM fuel cells. J. Mater. Chem. 2012, 22, 5444-5453. [CrossRef]

42. Søndergaard, T.; Cleemann, L.N.; Becker, H.; Aili, D.; Steenberg, T.; Hjuler, H.A.; Seerup, L.; Li, Q.; Jensen, J.O. Long-term durability of HT-PEM fuel cells based on thermally cross-linked polybenzimidazole. J. Power Sources 2017, 342, 570-578. [CrossRef]

43. Joseph, D.; Krishnan, N.N.; Henkensmeier, D.; Jang, J.H.; Choi, S.H.; Kim, H.-J.; Han, J.; Nam, S.W. Thermal crosslinking of PBI/sulfonated polysulfone based blend membranes. J. Mater. Chem. A 2017, 5, 409-417. [CrossRef]

44. Wu, C.-G.; Lu, M.-I.; Chuang, H.-J. PVdF-HFP/P123 hybrid with mesopores: A new matrix for high-conducting, low-leakage porous polymer electrolyte. Polymer 2005, 46, 5929-5938. [CrossRef]

45. Quartarone, E.; Magistris, A.; Mustarelli, P.; Grandi, S.; Carollo, A.; Zukowska, G.Z.; Garbarczyk, J.E.; Nowinski, J.L.; Gerbaldi, C.; Bodoardo, S. Pyridine-based PBI Composite Membranes for PEMFCs. Fuel Cells 2009, 9, 349-355. [CrossRef]

46. Pu, H.; Liu, L.; Chang, Z.; Yuan, J. Organic/inorganic composite membranes based on polybenzimidazole and nano-SiO 2 . Electrochim. Acta 2009, 54, 7536-7541. [CrossRef]

47. Fishel, K.J.; Gulledge, A.L.; Pingitore, A.T.; Hoffman, J.P.; Steckle, W.P., Jr.; Benicewicz, B.C. Solution Polymerization of Polybenzimidazole. J. Polym. Sci. Part A Polym. Chem. 2016, 54, 1795-1802. [CrossRef]

48. Galbiati, S.; Baricci, A.; Casalegno, A.; Marchesi, R. Degradation in phosphoric acid doped polymer fuel cells: A $6000 \mathrm{~h}$ parametric investigation. Int. J. hydrogen Energy 2013, 38, 6469-6480. [CrossRef]

49. Musto, P.; Karasz, F.E.; MacKnight, W.J. Fourier transform infra-red spectroscopy on the thermo-oxidative degradation of polybenzimidazole and of a polybenzimidazole/polyetherimide blend. Polymer 1993, 34, 2934-2945. [CrossRef]

50. Yu, S.; Zhang, H.; Xiao, L.; Choe, E.W.; Benicewicz, B.C. Synthesis of Poly (2,2'- (1,4-phenylene) 5,5'-bibenzimidazole) (para-PBI) and Phosphoric Acid Doped Membrane for Fuel Cells. Fuel Cells 2009, 9, 318-324. [CrossRef]

51. Ma, Y.L.; Wainright, J.S.; Litt, M.H.; Savinell, R.F. Conductivity of PBI Membranes for High-Temperature Polymer Electrolyte Fuel Cells. J. Electrochem. Soc. 2004, 151, A8-A16. [CrossRef]

52. Kreuer, K.-D.; Rabenau, A.; Weppner, W. Vehicle Mechanism, A New Model for the Interpretation of the Conductivity of Fast Proton Conductors. Angew. Chem. Int. Ed. 1982, 21, 208-209. [CrossRef]

53. Escorihuela, J.; Garcia-Bernade, A.; Compan, V. A Deep Insight into Different Acidic Additives as Doping Agents for Enhancing Proton Conductivity on Polybenzimidazole Membranes. Polymers 2020, 12, 1374. [CrossRef] [PubMed]

54. Jheng, L.-C.; Hsu, S.L.-C.; Tsai, T.-Y.; Chang, W.J.-Y. A novel asymmetric polybenzimidazole membrane for high temperature proton exchange membrane fuel cells. J. Mater. Chem. 2014, 2, 4225-4233. [CrossRef] 
55. Jheng, L.-C.; Chang, W.J.-Y.; Hsu, S.L.-C.; Cheng, P.-Y. Durability of symmetrically and asymmetrically porous polybenzimidazole membranes for high temperature proton exchange membrane fuel cells. J. Power Sources 2016, 323, 57-66. [CrossRef]

56. Jeong, Y.H.; Oh, K.; Ahn, S.; Kim, N.Y.; Byeon, A.; Park, H.-Y.; Lee, S.Y.; Park, H.S.; Yoo, S.J.; Jang, J.H.; et al. Investigation of electrolyte leaching in the performance degradation of phosphoric acid-doped polybenzimidazole membrane-basedf high temperature fuel cells. J. Power Sources 2017, 363, 365-374. [CrossRef]

(C) 2020 by the authors. Licensee MDPI, Basel, Switzerland. This article is an open access article distributed under the terms and conditions of the Creative Commons Attribution (CC BY) license (http://creativecommons.org/licenses/by/4.0/). 